Gut, 1966, 7, 708

\title{
The British Society of Gastroenterology
}

The annual meeting of the British Society of Gastroenterology was held at the Royal College of Surgeons of England and at the Postgraduate Medical School of London on 3 to 5 November 1966 with Dr. F. Avery Jones as President and Dr. J. E. Lennard-Jones as the local secretary.

The annual dinner was held at the Apothecaries' Hall.

At the annual general business meeting the following officers were elected:-

President-Elect: O. Fitzgerald

Hon. Treasurer: J. F. Dow

The following were elected Honorary Members:-

T. C. Hunt, G. Lambling.

The following were elected Ordinary Members:-

P. Fitzgerald, P. B. B. Gatenby, M. Langman, K. Lumsden, J. J. Misiewicz, R. Shield, W. P. Small, J. S. Stewart, E. J. Williams, K. G. Wormsley, A. C. Young.

The following were elected Associate Members:-

G. M. Andran, J. Bamforth, A. P. Barabas, V. S. Brookes, P. G. Collins, O. Craig, D. Croft, J. L. Dawson, F. T. de Dombal, R. H. Dowling, M. Eastwood, J. J. Fishlock, J. C. Gazet, A. D. Gough, M. J. Grayson, J. Griffiths, C. Holdsworth, W. Hindle, C. T. Howe, G. W. Johnston, J. Kilby, H. Kopelman, F. I. Lee, J. Levi, J. P. A. McManus, I. B. Macleod, M. P. Mahoney, C. N. Mallinson, T. S. Matheson, G. Neale, F. X. O'Connell, A. Parkin, P. I. Reed, J. C. Shearman, J. Spencer, J. E. Trapnell, G. Walker, D. G. Weir, B. J. Wilken, K. L. Williams.

\section{INSULIN AND GASTRIC SECRETION}

BASIL I. HIRSCHOWITZ In chronic fistula dogs with intact vagi, insulin-induced hypoglycaemia stimulates the gastric secretion of electrolytes and pepsin via the vagus. At the same time, insulin in doses greater than 0.45 units/ kg. inhibits the secretion of electrolytes $(\mathrm{H}, \mathrm{K}, \mathrm{Cl})$ and water. The inhibition is best seen when insulin is injected during a continuous maximal histamine infusion, lasts about three hours, and approaches $100 \%$ with doses of 0.6 to 0.9 units $/ \mathrm{kg}$. It also occurs in the absence of histamine stimulation and accounts for the double-peak or bimodal gastric secretory response to larger doses of insulin, i.e., inhibition by the insulin superimposed on the stimulation by hypoglycaemia. It is also found in the isolated guinea-pig gastric mucosa.

This inhibition can be very rapidly and completely reversed by the intravenous injection of $\mathrm{KCl}$ or $\mathrm{RbCl}$ $(0.5$ to $1.0 \mathrm{mEq} . / \mathrm{kg}$.) but not by glucose, glucagon, $\mathrm{NaCl}, \mathrm{CaCl}_{2}$, or $\mathrm{MgCl}_{2}$. These findings suggest that insulin, by direct action on the gastric mucosa, inhibits electrolyte secretion by diverting $\mathrm{K}^{+}$from a small essential cellular site which is concerned with the secre- tion of $\mathrm{H}, \mathrm{Cl}$, and $\mathrm{K}$ itself. This site appears to be similar to, if not identical with, the small compartment rapidly depleted by placing gastric mucosa in a $\mathrm{K}^{+}$-free solution.

\section{A NEW TEST FOR THE COMPLETENESS OF VAGOTOMY}

D. G. THOMAS AND H. L. DUTHE (Sheffield) Previous workers have described the use of 2-desoxy-D-glucose ( 2 D.G.) as a powerful stimulant of gastric secretion in dogs and man, being dependent on vagal innervation ${ }^{1,2}$. Early work indicates that as a gastric secretory stimulant this glucose analogue has certain advantages which may make it superior to insulin in the investigation of the vagal mechanisms of gastric secretion.

In the present study the use of insulin and 2 D.G. to indicate the completeness of vagotomy has been compared in 25 patients who have had a vagotomy and a pyloroplasty in the treatment of duodenal ulcer. The insulin tests were assessed according to Hollander's criteria and divided into positive and negative tests. The positive series was subdivided into early (within one hour) and late (after one hour) responses according to the timing of the increase of acid secretion after insulin.

Our findings confirm that the response to 2 D.G. depends on vagal innervation of the stomach and that it occurs within an hour. No late response (as found after the insulin test) was observed when 2 D.G. was given after incomplete vagotomy.

'Duke, W. W., Hirschowitz, B. I., Sacks, G. (1965). Vagal stimulation of gastric secretion in man by 2-deoxy-d-glucose. Lancet, 2 , 871-876.

'Eisenberg, M. M., Emas, G. S., Grossman, M. I. (1966). Comparison of the effect of 2-deoxy-d-glucose and insulin on gastric acid secretion in dogs. Surgery, 60, 111-117.

\section{PLASMA INSULIN LEVELS IN DUODENAL ULCER PATIENTS}

K. D. BUChANAN, M. T. McKIDDIE, and W. G. MANDERSON (Glasgow) Abnormalities of carbohydrate metabolism, especially hypoglycaemia, have been reported frequently in patients with peptic ulceration. Their aetiological significance has been disputed. More recently intestinal humoral factors have been implicated in the normal insulin response to oral glucose.

Standard $50 \mathrm{~g}$. oral and $25 \mathrm{~g}$. intravenous glucose tolerance tests were performed in 14 patients with duodenal ulcers and in 14 control subjects. Plasma insulin was assayed by the Hales and Randle immuno-assay technique. 
Mean blood sugar values after oral glucose were similar in the two groups except at 15 minutes when the level was significantly higher in the ulcer patients. Four of the ulcer patients and two controls developed secondary hypoglycaemia. Only one patient had a lag curve. Plasma insulin values after oral glucose were significantly higher in the ulcer patients than in the controls.

Following intravenous glucose there was no significant difference between the groups in either the glucose disappearance rate or the plasma insulin values. The peak insulin level reached in the two tests was similar in the control subjects but the ulcer patients showed a significantly higher response to the oral glucose.

Augmented histamine tests were performed in the ulcer patients. No correlation was found between either the volume of gastric secretion or the acid content and the insulin response to oral glucose.

'Hales, C. N., and Randle P. J. (1963) Biochem. J., 88, 137.

\section{HYPERPLASIA OF THE GASTRIC MUCOSA} PRODUCED BY DUODENAL OBSTRUCTION

G. P. CREAN, D. HOGG, AND R. D. E. RUMSEY (Edinburgh) The gastric outflow was obstructed in rats by tying a ligature around the duodenum about $1 \mathrm{~cm}$. distal to the pyloro-duodenal junction. The degree of obstruction was assessed at necropsy three to 11 weeks later and the volume (mass) of the gastric mucosa and the total parietal and peptic cell populations of the stomach were estimated $^{1,2}$. 'Moderate obstruction' caused striking increases in the mass of the mucosa both in the body and antrum of the stomach $(190-200 \%)$ and in the parietal and peptic cell populations (130-140\%). 'Overtight obstruction' caused more marked hyperplasia and gastric ulceration whereas 'ineffective obstruction' exerted no effects on the stomach.

'Cox, A. J., and Barnes, V. R. (1945). Proc. Soc. exp. Biol. Med. 60, 118.

'Card, W. I., and Marks, I. N. (1960). Clin. Sci., 19, 147.

\section{SEX, SEX HORMONES, AND GASTRIC ACID IN THE DOG}

J. H. BARON (London) In trained, unanaesthetized greyhounds with chronic gastric fistulas, acid output was stimulated by intravenous infusions of histamine acid phosphate over the dose range 1 to $16 \mu \mathrm{g} . / \mathrm{kg}$. $/ \mathrm{min}$. There were no significant differences for either submaximal or maximal acid outputs between dogs and bitches. Neither orchidectomy nor oophorectomy altered acid output. Chronic administration of stilboestrol, 1 or $2 \mathrm{mg}$. daily by mouth ( \pm progesterone $25 \mathrm{mg}$. i.m. three times a week) to the orchidectomized dogs, and of testosterone proprionate, $25 \mathrm{mg}$. twice weekly i.m. to the oophorectomized bitches, were without significant effect after one, three, six, or 12 months.

SOME OBSERVATIONS ON THE BIOASSAY OF STIMULANTS OF GASTRIC SECRETION IN RATS

A. M. BARRETT AND J. D. FITZGERALD (Pharmacology and Medical Departments, I.C.I. Ltd.) Synthesis of peptides having gastrin-like activity made it necessary to develop a rapid, reliable method for the estimation of their relative biological activity. Although not a popular animal for the study of gastric secretion, the rat has obvious advantages for this type of work. The first successful perfused rat stomach preparation adopted a technique of continuous recording of the $p H$ of a buffered perfusate (Ghosh and Schild, 1958). Whilst this technique is satisfactory for choline esters it does not give good results for gastrin-like peptides. The technique was modified by Lai (1964) for the assay of gastrin extracts but it has not been possible to obtain equally satisfactory results in our laboratory using Lai's method. The anaesthetic agent employed and the route of administration thereof have profound effects on the responses obtained. An assay using a $4 \times 4$ design has been used with some success, comparison of the total acid output per dose injected giving the most reproducible results.

\section{EFFECT OF A GASTRIN-LIKE PENTAPEPTIDE \\ ON GASTRIC SECRETION AND ON \\ GASTROINTESTINAL MOTILITY IN MAN}

J. J. MISIEWICZ, D. J. HOLDSTOCK, AND SHEILA L. WALLER (London) Stimulation of gastric and colonic motility has been described after single injections of gastrin or its pentapeptide analogue (I.C.I. 50, 123). In the present study the effect of a constant intravenous infusion of the pentapeptide on the motility of the stomach, the colon, and the rectum was investigated. The pentapeptide was administered at a rate which resulted in a near maximal secretion of gastric acid.

Intraluminal pressures were measured with polyethylene catheters in the gastric body and antrum, with radiotelemetering capsules in the ascending colon, and with small balloons in the sigmoid and the rectum. The pentapeptide was given intravenously at the rate of 0.01 and $0.1 \mu \mathrm{g} . / \mathrm{kg} . / \mathrm{min}$.

At $0.01 \mu \mathrm{g} . / \mathrm{kg} . / \mathrm{min}$. there was no effect on the motility of the right or the left colon or the rectum, but there was an increase in the activity of the antrum, which occurred simultaneously with the increase in gastric secretion. A higher dose of the drug resulted in only a small further increase in the output of gastric juice and did not produce any further changes in motility.

These results suggest that at dose levels resulting in near-maximal output of gastric juice, the apparent motor effects of the pentapeptide may be limited to the stomach.

\section{GASTRIN PENTAPEPTIDE AS AN INHIBITOR OF GASTRIC ACID SECRETION}

I. E. GILlespie AND S. P. MASTER (Glasgow) It has previously been shown that a single rapid intravenous injection of a large dose of gastrin extract can powerfully inhibit the acid response of a Heidenhain pouch dog to stimulation by the continuous intravenous infusion of gastrin or histamine ${ }^{1}$. Although the mechanism of this inhibition is unknown, it appears to be dependent on a critical concentration of circulating gastrin being obtained.

In the present experiments the synthetic gastrin-like pentapeptide I.C.I. 50,123 has been found to cause similar inhibition when given by rapid intravenous 
injection to Heidenhain pouch dogs. In the first part of the study the reproducibility of the inhibition was investigated. The minimal dose required to elicit $80 \%$ inhibition of the acid output to a near maximal dose of histamine was determined, and this dose was then given at repeated intervals as soon as secretion had returned to control levels. It was found that each repeat injection of pentapeptide was followed by an almost identical degree and duration of inhibition.

The rapid intravenous injection of the same dose of pentapeptide given at the peak of an acid response to a meat meal also caused profound inhibition. Finally it was possible to suppress completely the response to the meal by a series of timed pentapeptide injections.

${ }^{1}$ Gillespie, I. E., and Grossman, M. I. (1963). Inhibition of gastric secretion by extracts containing gastrin. Gastroenterology, 44, 301-310.

\section{EFFECT OF HISTAMINE, GASTRIN II, AND VAGOTOMY} ON INTRINSIC FACTOR SECRETION IN MAN

D. G. WEIR, I. J. TEMPERLEY, AND D. COLLERY (Dublin) The pattern of intrinsic factor secretion following continuous infusion of histamine and gastrin has been assessed. In both instances there is an immediate high output which is followed after the first hour by a low steady state secretion. The first hour secretion probably represents a 'washout phenomenon' and the second hour secretion the rate of formation of intrinsic factor. A significant correlation has been demonstrated between the first and second hour secretion of intrinsic factor and the maximal acid secretion. The relevance of these findings in respect of the site of origin of intrinsic factor from the gastric mucosa will be discussed.

Dose response relationships of intrinsic factor and acid secretion to varying doses of histamine and gastrin II have shown that maximal levels of both intrinsic factor and acid are obtained at $40 \mu \mathrm{g} . / \mathrm{kg}$. histamine and $1 \mu \mathrm{g}$./gastrin II per hour.

The 'maximal' level of secretion obtained following histamine infusion was $85 \%$ of the 'maximal' following gastrin infusion and subcutaneous histamine produced only $75 \%$ of the former.

The combined effect of vagotomy and pyloroplasty has been assessed by comparing the maximal secretion of acid and intrinsic factor before and after operation. Histamine-stimulated output falls by $60 \%$ in contrast to the gastrin-induced secretion which falls by less than $40 \%$.

\section{PHYSIOLOGICAL STUDIES ON THE PYLORIC BRANCH OF THE VAGUS}

J. E. BLACK (Belfast) The operation of selective gastric vagotomy was introduced in an attempt to abolish the undesirable side effects of total truncal vagotomy. Whilst it is agreed that the hepatic branch of the anterior vagus and the coeliac branch of the posterior vagus should be preserved, it is less certain as to whether the pyloric branch of the anterior nerve should be kept intact or divided.

The present paper reports experiments carried out to assess the influence of the pyloric nerves on gastroduodenal motility and gastric acid secretion.

The motility of the distal antrum and proximal duodenum was studied in dogs using miniature balloons introduced through metal cannulae. Insulin hypoglycaemia was used to stimulate the vagi. It was found that in animals with all vagal fibres intact insulin hypoglycaemia augmented the motility in the distal antrum but had no effect on the motility in the proximal duodenum. No evidence was found to suggest that the pyloric branch of the anterior vagus had any influence on gastric or duodenal motility.

In a second series of experiments acid secretion from the whole stomach, and the response of a Heidenhain pouch to meat extract instilled into the stomach, was studied. The results indicated that the pyloric nerves had no influence on gastric acid secretion.

\section{DUODENAL REFLUX AND GASTRIC SECRETION}

J. KILBY (Bristol) It has now been shown that duodenal juices in contact with gastric mucosa cause chronic superficial and atrophic gastritis. It therefore becomes of interest to know whether or not reflux is a factor in those conditions associated with a changing secretory pattern.

A test to demonstrate duodenal reflux is described, its validity assessed, and its limitations pointed out.

Results in 75 cases are described. Reflux cannot be demonstrated in normal stomachs or in early duodenal ulcer. It occurs commonly in gastric ulcer and longstanding duodenal ulceration.

It is concluded that the pylorus is incompetent when deformed by disease and that reflux may be an important factor producing a fall in acid secretion. The reasons for these changes are twofold. 1 Alkalisation of gastric juices occurs. 2 The attendant chronic superficial and atrophic gastritis produces a decreased oxyntic cell mass.

\section{MALIGNANCY IN ADULT COELIAC DISEASE AND IDIOPATHIC STEATORRHOEA}

O. D. HARRIS, W. T. COOKE, H. THOMPSON, AND J. A. H. WATERHOUSE (Birmingham) Two hundred and two patients with either adult coeliac disease or idiopathic steatorrhoea have been reviewed; of these patients, 136 had adult coeliac disease confirmed by jejunal biopsy and 66 had non-biopsied idiopathic steatorrhoea. They had been regularly followed up at hospital for a mean period of 8.2 years after diagnosis, and the mean duration of all symptoms attributed to either of these conditions was 24.4 years. Of the 77 dead patients, 59 ( 24 coeliac disease, 35 idiopathic steatorrhoea) had full necropsy examination; another six (two coeliac disease, four idiopathic steatorrhoea) had laparotomy, and another six (all coeliac disease) had jejunal biopsy. Fourteen developed lymphoma, 13 developed gastrointestinal carcinoma, and four developed other malignancies.

Of the 13 gastrointestinal carcinomata, six were oesophageal, three stomach, and one each from tongue, colon, rectum, and anus. One man developed both an oesophageal and anal carcinoma. The mean duration of coeliac symptoms before the diagnosis of carcinoma was 38.5 years. 
Of the 14 lymphomata, 10 were histologically reticulum cell sarcoma and four were Hodgkin's disease. The mean duration of coeliac symptoms before the diagnosis of lymphoma was $21 \cdot 2$ years.

When statistically compared with an age- and sexmatched population, the results are highly significant in both sexes for lymphoma, and highly significant in males but less significant in females for gastrointestinal carcinoma (especially oesophageal).

From this evidence it is concluded that malignancy (lymphoma or gastrointestinal carcinoma) is a significant complication of adult coeliac disease or idiopathic steatorrhoea.

\section{DIGESTION OF PROTEIN BY HUMAN SUBJECTS}

M. GAY AND C. W. CRANE (Birmingham) In earlier studies $^{1}$ it was shown that small quantities of ${ }^{15} \mathrm{~N}$ labelled yeast protein were rapidly digested and absorbed by normal subjects and that the hydrolysis of the protein in the gut did not appear to be the rate-determining step in the overall uptake.

These conclusions were reached from experiments from which absorption was followed by measuring the rates of labelling of urinary ammonia and urea and the labelling of the urea in peripheral venous blood. It was pointed out, however, that other factors such as the rate of stomach emptying, the rates of mixing of labelled amino acids and urea in the body, the speed of transfer of label from absorbed amino acids to glutamine, and the rate of excretion of ammonia and urea into the urine were factors which affected an estimate of the absorption of the protein determined in this way. In order to obtain further information, the problem has been re-investigated by measuring the isotope content of both amino acids and urea in hepatic venous and arterial or peripheral venous blood obtained from patients undergoing routine cardiac catheterization following the injection of whole protein or protein hydrolysate directly into the duodenum. The protein hydrolysate was absorbed extremely rapidly from the intestine, peak labelling of the amino acids occurring within a few minutes followed by an equally rapid fall. In addition the maximum labelling of the urea occurred at about five minutes. By contrast the maximum labelling of the amino acids in liver blood after giving whole protein was found between 20 and 30 minutes and that of the urea between $\mathbf{3 0}$ and $\mathbf{4 0}$ minutes. However, substantial labelling of the amino acids was detected 60 seconds after giving the labelled protein, and in one experiment this amounted to $25 \%$ of the peak value observed.

${ }^{1}$ Crane, C. W., and Neuberger, A. (1960). Biochem. J., 74, 313.

\section{VALUE OF MEASURING URINARY INDICAN EXCRETION}

G. NEALE AND S. TABAQCHali (London) Certain intestinal bacteria (especially $E$. coil, Bacteroides, and some strains of Klebsiella) produce indole from the degradation of tryptophan. Indole is then absorbed from either the small or large intestine and excreted in the urine as indoxyl sulphate (indican). The measurement of urinary indican may therefore provide an indirect assessment of the bacteriology of the intestinal tract and may be particularly helpful in the diagnosis of patients with stagnant loops of small intestine.

Using the method of Curzon and Walsh (1962) ${ }^{1}$ we have measured the urinary indican excretion by 50 control subjects and 172 patients with a wide variety of gastrointestinal disorders. Mean 24-hour urinary excretion in control subjects was $48 \pm$ S.D. $20 \mathrm{mg}$. Subnormal urinary indican excretion was found in three patients with diarrhoea due to disaccharidase deficiency in whom the normal colonic bacteria were largely replaced by lactobacilli. Raised levels, usually not exceeding $250 \mathrm{mg}$./24 hours, are found in patients with various types of steatorrhoea, e.g., coeliac disease without evidence of bacterial growth in the small bowel. In these patients the degree of indicanuria correlates with the degree of malabsorption except in chronic pancreatitis. Similar levels of indican excretion occurred in patients with bacterial proliferation in the small bowel, e.g., due to jejunal diverticulosis but with little or no steatorrhoea. Very high levels (up to $500 \mathrm{mg}$. $/ 24 \mathrm{hr}$.) were found when there was a combination of steatorrhoea and bacterial growth in the small intestine. Daily indican excretion by patients with the blind loop syndrome treated with antibiotics has been followed and correlated with improvement in absorptive function.

${ }^{1}$ Curzon, G., and Walsh, J. (1962). Clin. Chim. Acta, 7, 657.

\section{DEFICIENCY OF $\gamma$-MACROGLOBULIN IN COELIAC DISEASE}

J. R. HOBBS AND G. W. HEPNER (London) It has been suggested that lymphoreticular dysfunction may play an important part in coeliac disease. For this reason the concentration of immunoglobulins $-\gamma \mathrm{A}, \gamma \mathrm{G}$, and $\gamma \mathrm{M}$ ( $\gamma$-macroglobulin) -in such patients was measured, since these proteins are synthesized by the lymphoreticular cells.

The sera of 52 patients with coeliac disease were studied and the immunoglobulin levels measured by a modified Mancini method. Our hospital normal range is derived from 107 patients without diseases known to affect the immunoglobulins, and $\gamma \mathrm{M}$ values range from 45 to $180 \mathrm{mg} . / 100 \mathrm{ml} . \gamma \mathrm{M}$ deficiency is not uncommon and is the earliest immunoglobulin deficiency in many patients with lymphoreticular disease, possibly because $\gamma \mathrm{M}$ has the shortest half-life. Among the 52 cases with coeliac disease, $14(27 \%)$ had $\gamma \mathrm{M}$ levels of $45 \mathrm{mg} . / 100 \mathrm{ml}$. or less. In five cases mild $\gamma \mathrm{A}$ deficiency was found and in two of these $\gamma \mathrm{G}$ was also decreased. We have not encountered the complete $\gamma \mathrm{A}$ deficiency described by Crabbé and Heremans ${ }^{1}$.

Treatment with a gluten-free diet in six patients has resulted in restoration to normal level of the $\gamma \mathrm{M}$ in three. The clinical, biochemical, haematological, and histological features of the patients with $\gamma \mathrm{M}$ deficiency did not differ significantly from patients with normal levels. The evidence does not suggest that protein malnutrition or steatorrhoea plays an important part in causing the $\gamma \mathrm{M}$ deficiency. Although the serum albumin level was abnormal in some of the patients with coeliac disease, the level of serum albumin was unrelated to the level of $\gamma \mathrm{M}$. 
These findings support the theory that there is lymphoreticular dysfunction in some patients with coeliac disease.

${ }^{2}$ Crabbe, P. A., and Heremans, J. F. (1966). Gut, 7, 119.

\section{ALTERATION OF BILE SALT METABOLISM IN THE STAGNANT LOOP SYNDROME}

s. TABAQCHALI AND c. C. BOOTH (London) Disordered bile salt metabolism has been suggested as a possible cause for the steatorrhoea of patients with the stagnant loop syndrome. This could occur in two ways. 1 The conjugated bile salts could be broken down to deconjugated forms which are toxic to the intestinal mucosal. 2 The unconjugated bile salts may be ineffective in promoting fat absorption ${ }^{2}$.

To investigate these possibilities, bile salt metabolism was studied in patients with the stagnant loop syndrome and the effect of conjugated and unconjugated bile salt on intestinal absorption was assessed in experimental animals both in vivo and in vitro.

Twelve patients with the stagnant loop syndrome were studied and compared with normal control subjects. Thin-layer chromatography of the jejunal fluid revealed the presence of free bile acids, and quantitative measurements of these bile acids showed that deoxycholic acid was present in toxic concentrations.

The effect of similar concentrations of deoxycholic acid and of the infected jejunal fluid on the glucose absorption by rat intestine was studied. Although deoxycholic acid was found to be toxic to intestinal mucosa and to inhibit glucose absorption in vitro and in vivo, feeding of this substance to animals did not cause steatorrhoea.

The suggestion that the reduction of the concentrations of the conjugated bile salts to levels below the critical micellar concentration may be of aetiological importance in the causation of the steatorrhoea was also investigated by measuring the conjugated bile salts in these patients.

${ }^{1}$ Dawson, A. M., and Isselbacher, D. J. (1960). J. clin. Invest., 39, 730. ${ }^{2}$ Kim, Y. S., Spritz, N., Blum, M., Terz, J., and Sherlock, P. (1966). J. clin. Invest., 45, 956.

\section{PROTEIN METABOLISM IN THE INTESTINAL} BLIND LOOP SYNDROME

E. A. Jones, A. CRAigie, A. S. TAVIll, G. FRANGLEN, AND V. M. ROSENOER (London) Although the rate of synthesis of plasma proteins in the steady state can be measured indirectly by determining catabolic rates with labelled proteins, it cannot be measured over short periods or when synthesis and catabolic rates are changing rapidly. A modification of the method proposed by McFarlane (1963) for the direct measurement of the rate of synthesis of liver-produced plasma proteins, utilizing the labelling in vivo of the hepatic arginine pool by intravenously administered ${ }^{14} \mathrm{C}$-labelled sodium carbonate, has been used in the study of protein metabolism in a case of the intestinal blind loop syndrome.

The patient presented 10 years after an entero-enteric anastomosis had been performed for intestinal obstruction. The plasma albumin was $1.5 \mathrm{~g} . / 100 \mathrm{ml}$. The absolute albumin synthesis rate was $40 \mathrm{mg} . / \mathrm{kg}$. body wt./day using the arginine ${ }^{14} \mathrm{C}$ method. The absolute albumin catabolic rate of a specimen of ${ }^{125}$ I HISA was $25 \mathrm{mg} / \mathrm{kg}$. body wt./day (normal $190 \pm 40 \mathrm{mg}$./kg. body wt./day). The levels of the plasma amino acids were low.

Treatment with antibiotics resulted in a rise in the serum albumin to $3.3 \mathrm{~g} . / 100 \mathrm{ml}$. The levels of the plasma amino acids rose and the absolute albumin synthesis rate increased to $323 \mathrm{mg}$. $/ \mathrm{kg}$. body wt./day.

The data suggest that the hypoproteinaemia was largely due to the abnormal intestinal bacterial flora interfering with the utilization of dietary protein, resulting in a state of severe hypoanabolism. Excessive loss of protein from the blood into the intestine did not appear to be an important factor.

IRON METABOLISM IN CONGENITAL HYPERBILIRUBINAEMIA

PAUL SMITH, J. E. MIDDLETON, T. FREEMAN, AND ROGER WILlIAMS (Southampton and London) An unexpected finding during the investigation of a patient with a congenital unconjugated hyperbilirubinaemia (serum bilirubin level of $6.8 \mathrm{mg} . / 100 \mathrm{ml}$.) was a considerably raised serum iron level of $485 \mu \mathrm{g} . / 100 \mathrm{ml}$. The serum total iron-binding capacity (T.I.B.C.) was also raised though to a lesser extent and the percentage saturation of T.I.B.C. was markedly increased at $90 \%$. Subsequently another patient with a severe unconjugated hyperbilirubinaemia was found to have comparable levels of serum iron and T.I.B.C. and similar though less marked changes were found in five of nine patients with milder degrees of unconjugated hyperbilirubinaemia of the Gilbert variety.

The families of these 11 patients were also investigated. Of the 27 siblings and parents examined, 11 had a raised serum bilirubin level, and, of these, four had similar abnormalities in iron transport to those observed in the propositi. The findings suggested a dominant mode of inheritance with incomplete expression.

The changes in serum iron level could not be attributed to haemolysis or to increased body iron stores. Radioactive iron studies showed an increased plasma iron turnover suggesting the presence of an enlarged nonerythropoietic pool. On immunoelectrophoresis the transferrin showed normal mobility and the fractional breakdown rate of labelled transferrin was also normal. There was a curvilinear relation between serum iron and bilirubin levels.

\section{ULTRASONIC SCANNING OF THE LIVER}

C. F. MCCARTHY, P. WELLS, F. ROSS, K. T. EVANS, AND A. E. READ (Bristol) Ultrasonic scanning has been used in the diagnosis of various neurological, obstetrical, and ophthalmic disorders. Evidence of its value in the identification of hepatic disease is still meagre.

We have used the technique of two-dimensional ultrasonic scanning of the liver in both normal patients and those with liver disease. We have compared the intercostal and subcostal methods of scanning and for various reasons prefer the latter. In view of the fact that the liver tends to absorb ultrasonic signals we have found 
it necessary to employ a compensatory system to ensure a constant intensity of ultrasound at every depth in the liver.

The procedure is harmless to the patient and is without any form of discomfort. Further, repeated scans can be performed as they are required. The technique suffers from none of the disadvantages of liver biopsy or scintillography though it is probably less likely to pick up mild diffuse hepatic lesions. Ultrasonic scanning is an effective way of diagnosing neoplastic involvement of the liver, hepatic cirrhosis, and hepatic cysts and abscesses.

THE METABOLISM OF ${ }^{15} \mathrm{~N}$ AMMONIA IN NORMAL
SUBJECTS AND PATIENTS WITH LIVER DISEASE

W. D. STONE, M. GAY, AND C. W. CRANE (Birmingham) Many studies have shown that patients with liver disease metabolise ammonia abnormally but the relative contribution of such factors as hepatocellular disease, portocaval shunting, and defective peripheral uptake remain to be assessed.

In order to obtain some information on these points, ${ }^{15} \mathrm{~N}$-labelled ammonium lactate (30 atom \% excess) was given to four patients with liver disease and to two normal subjects in amounts equivalent to $0.4 \mathrm{mg}$. of ${ }^{15} \mathrm{~N} / \mathrm{kg}$. body weight. All patients had some degree of shunting which resulted in the excretion directly into the urine of a proportion of the absorbed ${ }^{15} \mathrm{~N}$-labelled ammonia. The labelling of the ammonia in urine collected during the first hour of each study was high, and, in experiments with two patients who had large shunts, reached values above 4.0 atom $\%{ }^{15} \mathrm{~N}$ excess. On the other hand, the labelling of the urea was related to liver function as assessed by conventional means and this also appeared to determine the amounts of ${ }^{15} \mathrm{~N}$ appearing in the ammonia and urea excreted during the first six hours. Our tentative conclusions are that poor liver function rather than porto-systemic shunting is a more important factor in the failure to detoxicate administered ammonia to an inert metabolite.

\section{PSYCHOGENIC VOMITING}

o. W. HILL (London) Thirteen patients with recurrent vomiting, for which no organic cause could be demonstrated, were examined from the psychological point of view. Of these patients, eight had been referred chiefly because of vomiting and the other five came from a series of patients referred for psychogenic abdominal pain who also vomited.

The following observations were made:

1 Of the nine who were currently married, seven were living in a state of gross overt antagonism to their spouse. Of the four unmarried patients, three were living with parents to whom they felt marked hostility but whom they felt they could not leave. Eight of the patients lost a parent by death before achieving the age of 13 .

These findings were highly significant when compared with a control group derived from patients suffering from psychogenic abdominal pain and referred in the same way as the above patients for psychiatric assessment.
2 Of the eight patients whose major problem was vomiting, five had recurrent episodes of vomiting in childhood and the sixth had vomited for six months at the menarche.

3 In three of the patients the serum potassium was below $3.5 \mathrm{mEq}$./1. and all three gave a history of limb paresis.

\section{THE EFFECT OF OESOPHAGEAL PERFUSION OF ACID ON BASAL GASTRIC SECRETION}

G. R. GILES AND C. G. CLARK (Leeds) The oesophagus and the duodenum are both at risk to the ulcerogenic potential of gastric secretions. In the duodenum there are inhibitory mechanisms which offer some protection, and these are stimulated by acid passing into the duodenum. This study reports the effects on gastric secretion of perfusing acid in the oesophagus.

A simple technique was used to locate the oesophagogastric junction, and oesophageal perfusion was performed $10 \mathrm{~cm}$. proximal to this. Gastric secretions were collected before and during perfusion. Studies were performed in 12 normal subjects, eight patients with duodenal ulceration and 15 patients with hiatus hernia, and the perfusion was performed with water or hydrochloric acid labelled with a non-absorbable dye.

The results show that gastric secretion is stimulated by acid perfusion of the oesophagus. In some subjects the increased volume is mainly accounted for by the nonparietal component. In patients with hiatus hernia and oesophagitis, perfusion often caused symptoms, and the increase in acid output in the patients contrasted markedly with the results in patients who remained asymptomatic.

\section{DRINKING TIME IN DYSPHAGIAS}

D. A. W. EDWARDS (London) The time taken to drink $400 \mathrm{ml}$. water as quickly as possible has been recorded in control subjects without cause for dysphagia; in achalasia before treatment and after dilatation and cardiomyotomy; in subjects with benign and malignant strictures of the oesophagus, including those mimicking achalasia; and in systemic sclerosis. The test is useful in distinguishing achalasia; as a measure of the restriction of outflow of fluid in achalasia; and in demonstrating that dilatation is a less effective treatment than cardiomyotomy. In benign strictures, strictures after cardiomyotomy for achalasia, and those malignant strictures which have not yet obliterated the lumen, the drinking time is normal, as it is in subjects without a peristaltic wave because of systemic sclerosis. The test does not measure the degree of dysphagia for solids. The oesophagus in achalasia behaves like a tube closed by an elastic process of various tensions; the strictures behave like rigid open tubes.

\section{EFFECT OF SUBDIAPHRAGMATIC VAGOTOMY ON THE FUNCTION OF THE GASTRO-OESOPHAGEAL SPHINCTER}

D. A. K. WOODWARD, J. ALEXANDER WILlIAMS, AND M. ATKINSON (Birmingham and Worcester) Gastro-oesophageal reflux has been reported in a high proportion of 
patients after abdominal vagotomy for duodenal ulcer ${ }^{1}$.

In 18 patients undergoing vagotomy and pyloroplasty for duodenal ulcer a manometric and radiological study has been made of the lower oesophagus and hiatus.

In 11 patients open-ended, water-filled tubes were used to measure the pressure in the lower oesophageal sphincter before and after operation. Post-operatively there was no change in two, a marked reduction in sphincter pressure in eight, and an absent sphincter in one. On all occasions where a sphincter was demonstrated it was situated below the diaphragm, as indicated by the point of respiratory reversal. In 10 patients clips were applied at operation to the hiatus and gastro-oesophageal junction and in nine of these subsequent radiographs showed that the cardia remained well below the hiatus. Of nine patients with no pre-operative reflux shown radiologically, six showed reflux after operation.

These studies suggest that oesophageal reflux, commonly found after vagotomy, is due to decrease in tone of the intrinsic lower oesophageal sphincter and further support the hypothesis that this sphincter is important in maintaining normal gastro-oesophageal competence.

${ }^{1}$ Clark, S. D., Penry, J. B., and Ward, P. (1965). Lancet, 2, 824.

\section{ANAEMIA AND HIATUS HERNIA}

COLIN W. O. WINDSOR AND J. LEIGH COLLIS (Birmingham) Evidence of gastrointestinal haemorrhage was found in 59 of 400 consecutive patients requiring operation for hiatus hernia. Of these 59,35 had iron-deficiency anaemia (mean $\mathrm{Hb} 8.5 \mathrm{~g}$.) and 24 melaena or haematemesis.

Gastrointestinal bleeding is significantly more common in the non-refluxing paraoesophageal (22 out of 74 , $30 \%$ ) than with sliding hernia (37 out of $326,11 \%$ ). There was no correlation between bleeding and oesophagoscopic diagnosis of oesophagitis. Dietary iron deficiency and other sites of blood loss were excluded.

Five gastric ulcers at the point where the stomach crossed the edge of the right crus were found. Subsequent observation of this site at operation has revealed petechial subserosal haemorrhages in five of six anaemic patients.

Operation cured anaemia (mean rise $\mathrm{Hb} \quad 5.4$ g.) and prevented further frank haemorrhage in all cases (follow up one to 13 years).

It is proposed that the cause of anaemia in patients with hiatus hernia is not oesophagitis, but trauma to the stomach where it rides to and fro against the crus during respiration leading to changes ranging from petechial haemorrhage to ulceration. The term 'riding ulcer' is introduced to describe this type of gastric ulcer.

${ }^{1}$ Collis, J. L. (1961). Thorax, 16, 114.

\section{GASTRIC MUCOSA AND SUSCEPTIBILITY TO OCCULT GASTROINTESTINAL BLEEDING CAUSED BY ASPIRIN}

D. N. CROFT AND PHILIP H. N. WOOD (London) Following repeated aspirin ingestion $78 \%$ of 226 subjects with a normal upper gastrointestinal tract bled more than $2 \mathrm{ml}$. per day as measured by the ${ }^{51} \mathrm{Cr}$-labelled red cell technique. To determine the lesion responsible for this bleeding five volunteers were given repeated doses of soluble aspirin for two to four days before elective partial gastrectomy. All resected specimens contained acute haemorrhagic erosions compared with only one of a control series. Dispersions of soluble aspirin caused exfoliation of gastric columnar cells both in normal volunteers and in patients known to bleed occultly after aspirin. It is suggested that erosions form when aspirin causes a greater rate of loss of cells than the mucosa is able to replace.

Eight subjects who bled $2 \mathrm{ml}$. or less per day after repeated aspirin ingestion were investigated by an aspirin gastric-DNA test. These non-bleeders appeared to have higher turnover of gastric cells and a higher incidence of atrophic gastritis than seven aspirin bleeders also investigated. Analysis of clinical data of the 226 subjects demonstrated amongst non-bleeders a significantly higher incidence of achlorhydria and biopsyproven atrophic gastritis. High turnover of epithelial cells, such as occurs in atrophic gastritis, may enhance mucosal resistance to aspirin as measured by occult bleeding.

\section{A TRIAL OF GASTRIC COOLING FOR HAEMATEMESIS}

J. B. MCFARLAND AND J. G. GOW (Liverpool) There has been a measure of support for Wangensteen's (1958) ${ }^{1}$ suggestion that depression of intragastric temperature to about half the normal is useful in controlling massive upper gastrointestinal haemorrhage. However, objective assessment of the method has been hampered by the difficulty of making a controlled comparison with other methods of management. Also there have been limitations in the safety and simplicity of the hypothermia apparatus used by some workers.

A two-year study of the use of a new and simple hypothermia system is described. The physicians and surgeons of a large general hospital cooperated in allowing patients with massive gastroduodenal haemorrhage to be randomly selected for management to include initial gastric cooling or to be along conventional lines. During the same period patients with severe persistent bleeding, with serious systemic complications in many cases, were accepted for management by elective gastric cooling.

The hypothermia apparatus proved to be most satisfactory. Critical analysis of the results showed that initial gastric cooling offered no advantage over conventional methods. However, in cases where serious complications precluded operation the technique did prove to be a useful alternative.

'Wangensteen, O. H., Root, H. D., Jenson, C. B., Imamoglu, K., and Salmon, P. A. (1958). Depression of gastric secretion and digestion by gastric hypothermia: its clinical use in massive haematemesis. Surgery, 44, 265.

THE TREATMENT OF ORGANO-AXIAL GASTRIC VOLVULUS DUE TO EVENTRATION OF THE DIAPHRAGM

NORMAN C. TANNER (London) Over the last 18 years, 21 cases of organo-axial volvulus of the stomach, associated with eventration of the diaphragm, have been dealt with in this clinic. 
The symptoms produced are rarely severe or urgent. Nonetheless their persistence and failure to react to placebo therapy lead to undue depression and anxiety. The condition has been treated in the past either by partial gastrectomy, which is unduly severe, or by simple gastropexy.

It is suggested that in the treatment of this condition the first requirement is to fill the subphrenic space with an organ which will replace the rotated stomach; the second requirement is to remove the drag of the colon on the greater curve of the stomach which rotates it forward and upward; and least important is a means of gastric fixation. These three objects can be simply attained by dividing the gastro-colic omentum widely and freeing the transverse colon so that it can float freely to fill the subphrenic space and no longer draws the greater curve of the stomach with it. A simple gastropexy, fixing the lesser curve of the stomach to the ligamentum teres, is then all that is required.

In cases where breathlessness is the prominent feature, a direct operation on the diaphragm may be indicated.

\section{EARLY SURGERY IN THE MANAGEMENT OF SEVERE ULCERATIVE COLITIS}

J. C. GOLIGHER, F. T. DE DOMBAL, N. G. GRAHAM, AND G. WATKINSON (Leeds) This paper presents an analysis of the outcome of 205 severe attacks of ulcerative colitis treated between 1952 and 1966. A comparison is made between the outcome of 81 such attacks treated between 1964 and 1966, when surgical aid was invoked at an early stage if there was no response to a short course of intensive conservative measures; and 124 attacks treated during 1952 and 1963, when the same conservative measures were employed, but when operative treatment was resorted to less readily.

The overall mortality in severe attacks during 1964 and 1966 was $1.2 \%$, significantly less than the $11.3 \%$ overall mortality during the previous decade. During 1964 and 1966 no patient died in a severe first attack; and no patient over 60 years of age died in a severe attack, whereas the comparable fatility rate for such elderly patients in severe attacks during 1952 and 1963 was no less than $50 \%$.

These findings strongly suggest that early radical surgical treatment may have considerable advantages for patients with severe attacks of colitis which fail to respond rapidly to intensive conservative measures.

\section{EOSINOPHILIC GRANULOMA OF THE GASTROINTESTINAL TRACT}

P. R. SALMON AND J. W. PAUlley (Ipswich) Eosinophilic granuloma of the gastrointestinal tract is regarded as part of a systemic, variable host response to a number of non-specific allergens. One in four of all reported cases show evidence of systemic allergy, with associated angioneurotic oedema, eosinophilic peritonitis, pericarditis, and pleurisy occurring with some frequency.

Previous arguments as to whether eosinophilic granuloma of the bowel is primarily a local phenomenon or part of a systemic allergic reaction may be irrelevant and dependent on the extent of the host response, and the site and mode of allergic insult. For example, those in the pyloric antrum usually give rise to pyloric stenosis either directly or by prolapsing into the duodenum, whilst the primary infiltrative type involving any part of the bowel may be associated with a variety of systemic allergic conditions and high blood eosinophil counts.

Three cases are discussed and 122 cases in the world literature are analysed with respect to the site and extent of the lesions and possible aetiology. The dramatic response to steroids, in cases not operated on, is emphasized.

\section{COELIAC SYNDROME AND GLUTEN WITHDRAWAL: AN ANALYSIS OF RESPONSE AND FAILURE}

I. J. PINK AND B. CREAMER (London) Fifty-four patients with the coeliac syndrome have been treated by a glutenfree diet and their subsequent course assessed. About $75 \%$ of the patients responded swiftly and definitively to this treatment and regained full health within three months. This leaves a sizable number in whom the response was unsatisfactory or completely negative. An analysis of these cases reveals three patterns of failure.

1 Complete refractoriness and a progressive downhill course: in this group the histological lesion is severe, extensive, and perhaps irreversible.

2 A failure to respond with persisting ill-health but no marked or early deterioration: in this group the histological lesion is accompanied by pancreatic deficiency.

3 A partial response but failure to regain full health: this group is not uniform and contains some instances of dietetic indiscretion.

In each of these groups the clinical, biochemical, or histological features followed separate patterns and have afforded some explanation of these failures. In groups 1 and 2 prediction of failure is sometimes possible. Attention is drawn to the mortality of this syndrome.

\section{SOME EFFECTS OF GASTRIC SURGERY ON NUTRITION}

ALAN G. Cox (Glasgow) In 1954, the Peptic Ulcer Clinic at the Western Infirmary, Glasgow, initiated a clinical trial in male patients with chronic duodenal ulcer requiring surgery. The purpose of the trial was a comparison of vagotomy with gastrojejunostomy against the Polya partial gastrectomy, the choice of procedure in the individual patient being made by random allocation. These patients have been carefully followed up since operation, and the present paper reports some of the results in the latest study, in which particular emphasis was placed on measurements of nutrition and diet. Early analysis indicates that some of the differences between the two operations have been exaggerated.

\section{VITAMIN E DEFICIENCY AFTER GASTRIC SURGERY}

M. S. LOSOWSKY, P. J. LEONARD, J. KELLEHER (Leeds), AND C. N. PULVERTAFT (York). In view of the oecurrence of malabsorption and deficiency of vitamin $\mathbf{D}$ after gastric operations, it seemed possible that deficiency of vitamin $\mathrm{E}$, which is also fat soluble, might likewise be found after 
surgery for peptic ulcer. Evidence of vitamin $E$ deficiency was sought in low plasma vitamin $\mathrm{E}$ levels and abnormal haemolysis of red cells by hydrogen peroxide.

Of 500 unselected patients attending a gastric followup clinic, the overall incidence of an abnormal plasma vitamin $\mathrm{E}$ level was $34 \%$. In most of these subjects the red cell haemolysis test was abnormal too. Evidence of deficiency of vitamin $E$ was found after all types of surgery for peptic ulcer, and was more common the longer the period since operation.

In 11 subjects with vitamin $\mathrm{E}$ deficiency investigated on a metabolic ward, it was shown that low plasma vitamin $E$ levels and abnormal haemolysis tests could be rapidly corrected by administration of pure $\alpha$ tocopherol. In 10 of these subjects there was abnormal creatinuria which also responded to therapy.

No attempt has yet been made to correlate symptoms or signs with the biochemical findings.

These findings suggest that deficiency of vitamin $E$ may be not uncommon after gastric surgery and that the possibility of deleterious effects should be considered, so that the desirability of replacement therapy can be assessed.

\section{THE EFFECT OF DIET UPON THE TRYPSIN AND CHYMOTRYPSIN OUTPUT IN HUMAN INTESTINAL CONTENTS}

A. D. ROY AND D. M. GOLDBERG (Glasgow) Trypsin and chymotrypsin have been measured in the drainage material from patients with an established ileostomy under controlled metabolic and dietary conditions. The weight of each sample was carefully taken and enzyme activity estimated on homogenates, and on the supernatant liquor prepared by low-speed centrifugation of homogenates, using specific model peptide substrates and a Ph-stat technique.

Small differences which were not significant occurred when the fat and the carbohydrate content of the diet was altered. The weight of the drainage material increased by $17.4 \%(P<0.01)$ when the subjects changed from a diet of $40 \mathrm{~g}$. protein to one of $90 \mathrm{~g}$. protein. Simultaneously, the daily output of trypsin in the homogenates increased by $71.2 \%(P<0.02)$ and the output of chymotrypsin by $21.5 \%(P<0.05)$. Because of binding of the enzymes to insoluble debris, these changes were not so pronounced in the supernatant preparation, trypsin being increased by $44.1 \%(\mathrm{P}<0.05)$ and chymotrypsin by $5.7 \%$ (not significant).

These results suggest that protein alone of the dietary constituents examined influences the quantity of those enzymes that reach the terminal ileum, and confirm that, in man, protein is the main stimulant to the production and secretion of pancreatic proteases.

\section{FAMILIAL PANCREATITIS}

MARTIN CAREY AND O. FITZGERALD (Dublin) The purpose of this paper is to report two contrasting families with a high incidence of chronic pancreatitis.

'B' FAMILY Reports of the rare occurrances of hereditary pancreatitis by Cross and Comfort 1,2 and Comfort and Steinberg $^{3}$ stimulated an investigation of the family of two sisters who had had repeated attacks of pancreatitis proven at laparotomy. In four generations of this family two members have definite chronic pancreatitis proven at laparotomy and seven have suspected pancreatitis, including two patients who had abnormally high serum amylase levels while experiencing an attack of abdominal pain. On investigation, serum calcium levels of $12.0 \mathrm{mg} . \%$ and $12.2 \mathrm{mg} . \%$ with correspondingly low serum phosphate levels were discovered in two cases, one with proven pancreatitis and the other with a history of recurrent pyelonephritis. The serum alkaline phosphatase level was constantly raised in another who had a borderline serum calcium concentration. There was no history of renal calculus in any patient. A lysine-cystine amino aciduria was present in all those examined, and bone and straight abdominal radiographs were normal in four members. All other investigations were normal; there was no other evidence in any patient of hyperparathyroidism or other endocrine adenoma.

Hereditary hyperparathyroidism associated with recurrent pancreatitis has only been reported once before ${ }^{4}$. The diagnosis here has been substantiated by repeated chemical abnormalities.

' $F$ ' FAMILY In this family two members (father and daughter) had surgically proven chronic pancreatitis and two had clinically suspected pancreatitis. Lysinuria was present in only one member. However, seven patients in this family had radiologically proven peptic ulceration in three generations and in those with pancreatitis the ulcer was shown to antedate the pancreatitis in all except the propositus. Four members had diabetes mellitus without complicating pancreatitis.

${ }^{1}$ Cross, J. B., and Comfort, M. W. (1956). Amer. J. Med., 21, 596. ${ }^{2}$ Cross, J. B., and Comfort, M. W. (1957). Gastroenterology, 32, 829. 'Comfort, M. W., and Steinberg, A. G. (1952). Gastroenterology, 21, 54.

‘Jackson, C. E. (1958). Amer. J. Med., 49, 829.

\section{STUDIES ON EXPERIMENTAL CHOLELITHIASIS IN RABBITS}

JAMES W. FRESTON, IAN A. D. BOUCHIER, AND M. O'GRADY (London) An experimental model for cholelithiasis has been used to examine factors of significance in lithogenesis. Cholelithiasis was induced by feeding rabbits a $0.75 \% \beta$-cholestanol diet. Control animals and vagotomized and sham-operated animals fed the lithogenic diet were studied. Stone weight, bile concentration and total hexosamines content of bile and stones were determined, and the biliary tree was examined histologically.

Gallstones were found in all the animals fed the diet for at least two weeks. The stones ranged in diameter from $<1 \mathrm{~mm}$. to $5 \mathrm{~mm}$., frequently filling the gallbladder. All the stones contained hexosamines, and an increase of goblet cells and P.A.S.-staining material was present in the biliary tree. No evidence of inflammation was found. These results suggest that mucus production is increased in the presence of cholelithiasis, independent of cholecystitis.

Occlusion of the cystic duct was associated with stones of greater weight than when the cystic duct was patent. 
Duct impaction was less frequent in vagotomized rabbits. Their gall bladders were larger and contained more bile. The total weight of gallstones was reduced compared to sham-operated animals.

\section{OESTROGENS AND HIGH-PROTEIN AND HIGH-CARBOHYDRATE DIETS IN THE TREATMENT OF DUODENAL ULCER}

A. M. CONNELL, J. FLETCHER, J. HOWEL JONES, M. J. S. LANGMAN, J. E. LENNARD JONES, AND F. PYGOTT (London) The synthetic oestrogen stilboestrol is one of the few drugs which has been shown objectively to be of value in the treatment of duodenal ulcer. Since this investigation has never been repeated further studies have been performed on the effects of the oestrogen, oestriol, on the symptoms and radiological healing of duodenal ulcer in men.

The trial was designed factorily to allow simultaneous comparison of high-protein and high carbohydrate diets, both of which have been suggested as of possible value in the treatment of ulcer. Forty-two patients were admitted to the trial and were treated with oestriol $1 \mathrm{mg}$. b.d. or a dummy tablet for six months, combined with a high-protein or high-carbohydrate diet. At the conclusion of the trial it was found that patients treated with oestriol or with a high-protein diet had slightly fewer days of pain during treatment than did those given dummy tablets or a high-carbohydrate diet, but the differences were small and could well have been due to chance. The radiological results were, in general, very poor, only one ulcer being observed to heal, and the findings in this trial contrast with the better results obtained in other studies even with dummy tablets. The cause of this difference is unknown, but it may be associated with variations in the types of patient admitted to the trials and to the difficulties of radiological assessment.

\section{POTASSIUM SECRETION BY RAT COLON}

c. J. EDMONDS (London) The potassium content of stool water is much greater than that of the blood and can vary considerably in different physiological states. Comparison of the potassium content of faeces taken from different parts of the rat colon with the electrical potential differences (p.d.) across the colon wall shows that the electrical gradient is not adequate to account for the faecal concentration of potassium. Water absorption occurs throughout the colon and could account for the concentration of potassium if the colonic epithelium were relatively impermeable to potassium. Perfusion of colon segments of anaesthetized rats was therefore done to measure (1) the unidirectional potassium fluxes using $\mathrm{K}^{42} \mathrm{Cl}$ and (2) the luminal concentration of potassium at which the fluxes were equal. Comparison of the results with those expected from the electrochemical activity of potassium on each side of the mucosa indicates that the colonic epithelium is actively secreting potassium into the lumen.
A METHOD OF SERIAL PORTAL VENOUS SAMPLING: ITS USE IN THE DEMONSTRATION OF MACROMOLECULAR ABSORPTION FROM THE HUMAN COLON

DOUGLAS M. MILlAR AND BRYAN N. BROOKE (London) Evidence of intestinal absorption can be obtained by direct sampling of the portal blood in human subjects as an incidental to abdominal operation. Repeated needle puncture of the portal vein is undesirable and it is difficult to obtain good serum samples from the smaller portal venous radicals. A simple and safe method of catheterization to obtain portal venous blood is described which does not materially interfere with the definitive operative procedure or lengthen the operating time.

The method is of value where the indirect means of estimating absorption are inconclusive. It has been applied to the demonstration of macromolecular absorption from the human colon in cases of ulcerative colitis, the procedure being carried out at the time of colectomy.

\section{THE RATE OF GASTRIC EMPTYING IN GASTRO-DUODENAL DISEASE}

G. H. GRIFFITH, G. M. OWEN, AND R. SHIELDS (Cardiff) There is no satisfactory method of measuring the time taken for food to leave the stomach. The serial test meal ${ }^{1}$ is not suitable for clinical use, and the use of meals containing radio-opaque substances is open to serious criticisms.

The rate of gastric emptying has been measured using a standard meal labelled with ${ }^{51} \mathrm{Cr}$. The radioactivity in the stomach was measured by scanning the upper abdomen at intervals, and the rate of emptying was calculated from the rate of disappearance of the isotope from the stomach ${ }^{2}$.

Eighty patients have now been investigated with this technique.

The data have been subjected to regression analysis by computer, and the validity of the exponential ${ }^{1}$ and square-root ${ }^{3}$ hypotheses of gastric emptying has been tested. The data fit both mathematical descriptions of emptying but in a small majority of patients the squareroot hypothesis was more accurate.

Gastric emptying was found to be more rapid than normal in patients with duodenal ulcer, except when the ulcer was complicated by pyloric stenosis. There was no significant delay in emptying in patients with gastric ulcer, and no correlation could be found between the emptying rate and the site of the ulcer, or between the emptying rate and the gastric acid output obtained by the histamine infusion test ${ }^{4}$.

In a further series of patients the rate of gastric emptying has been measured before and after vagotomy with pyloroplasty for duodenal and gastric ulcer.

${ }^{1}$ Hunt, J. M., and Spurrell (1951). J. Physiol. (Lond.), 113, 157.

${ }^{2}$ Griffith, G. M., Owen, G. M., Kirkman, S., and Shields, R.(1966). Lancet, 1, 1244.

'Hopkins, A. (1966). J. Physiol. (Lond), 182, 144.

'Lawrie, J. H., Smith, G. M. R., and Forrest, A. P. M. (1964). Lancet, $2,270$. 
A NEW METHOD OF STUDYING GASTRIC, SMALL INTESTINAL, AND TOTAL INTESTINAL TRANSIT TIMES

R. P. ROSSWICK, R. D. STEDEFORD, AND BRYAN N. BROOKE (London) A simple bedside method of measuring intestinal transit time has been devised. This requires no special preparation of the patient, who can eat normally and be active between observations.

A small quantity of ${ }^{131}$ I (less than $10 \mu \mathrm{c}$.) is incorporated in an araldite capsule, which also contains some lead to render it radio-opaque. A perspex grid is placed over the abdomen and the position of the 'pill' within the intestinal tract is determined by using a portable sodium iodide scintillation counter. Screening of the counter ensures accurate localization to within $1 \mathrm{~cm}$. The vertical and horizontal coordinates are read off the grid and plotted. Utilizing this method it is possible to determine gastric emptying times and small intestinal transit times with accuracy, and thus obtain accurate subdivisions of the total transit time without special preparation of the patient, or radiology.

Twenty-one patients (eight controls and 13 abnormals) have been studied. The 'abnormals' were principally patients suffering from ulcerative colitis or Crohn's disease. The results suggest that in ulcerative colitis the gastric emptying time is prolonged, but that it is normal in Crohn's disease.

\section{A NEW METHOD FOR MEASURING GUT TRANSIT TIMES}

J. M. HINTON (London) None of the methods used in the past for measuring the rate of passage of food residues through the gut is entirely satisfactory. Those using solid markers, like glass beads, necessitate sieving the stools, and those using easily visible markers, such as barium and carmine, cannot easily be quantitated.

A method has been devised in which pellets of bariumimpregnated polythene are used as markers. Pellets of more than one size may be used. The stools are collected in transparent plastic bags which are sealed and not re-opened. The stools are then radiographed and the radio-opaque pellets counted. The transit rate may then be expressed as the times taken by various percentages of the administered markers to pass through the gut. The passage of the markers through the colon may also be observed by taking serial radiographs of the subject. 